\title{
Erosion behaviour of hydro turbine steels
}

\author{
AKHILESH K CHAUHAN, D B GOEL* and SATYA PRAKASH \\ Department of Metallurgical and Materials Engineering, Indian Institute of Technology, Roorkee 247 667, India
}

MS received 27 November 2007; revised 24 December 2007

\begin{abstract}
The martensitic stainless steel (termed as 13/4) is currently being used for fabrication of underwater parts in hydroelectric projects. There are, however, several maintenance problems associated with the use of this steel. A nitronic steel (termed as 21-4-N) has been developed as an alternative with the specific aim of overcoming these problems. A comparative study has been made on the erosion behaviour of 13/4 and 21-4-N steels by means of solid particle impingement using gas jet. The eroded surfaces after erosion tests were analysed by scanning electron microscopy. It is observed that the 21-4-N nitronic steel possesses better resistance to erosion in comparison to $\mathbf{1 3 / 4}$ martensitic stainless steel. The austenitic matrix of the nitronic steel possesses high hardness, high tensile toughness and work hardening ability, which results in higher erosion resistance.
\end{abstract}

Keywords. In situ strain hardening; solid particle erosion; tensile toughness; 13/4 martensitic stainless steel; 21-4-N nitronic steel.

\section{Introduction}

Erosion due to impact of hard and abrasive particles is a common phenomenon in hydro turbine underwater parts and many other industrial situations. Extensive investigations (Ness and Zibbell 1996; Mann 1998, 2000) have been carried out in the past to identify the factors responsible for severe erosive damages in hydro turbine underwater parts due to attack from silt laden water. A number of operating variables such as the impact angle and impact velocity affect the erosion process (Finnie 1960; Sheldon and Kanhere 1972; Divakar et al 2005; Oka et al 2005). The rate of erosion is influenced by the relative hardness of the target material and the particles impacting on the surface (Divakar et al 2005). Ductile materials during erosion are considered to loose material through a cutting and ploughing mechanism at a low impact angle (Sheldon and Kanhere 1972). On the other hand, erosion damage of brittle materials is based on cracking, fragmentation and removal of flakes (Finnie 1960). The erosion mechanism in terms of mechanical properties was presented by Bitter (1963). He described that during impact, when the yield strength of the materials is locally exceeded, plastic deformation takes place in the vicinity of the impact. After multiple impacts, a plastically deformed surface layer may form near the eroded surface and, therefore, the yield strength of the material increases due to work hardening. Sundararajan and Shewmon (1983) suggested that during erosion material loss from a metal surface occurs when a critical fracture strain is achieved at the surface.

*Author for correspondence (dbgmtfmt@iitr.ernet.in)
Ball (1983) proposed that, in order to design a material to resist erosion, attention must be given to providing a microstructure that never accumulates the critical fracture strain under the stress that the impacting particles impose.

The cast martensitic stainless steels currently find wide applications in many hydro turbine and other industrial applications facing damages due to erosion. This is due to their good mechanical properties and resistance against corrosion and erosion. CA6NM steel containing $13 \% \mathrm{Cr}$ and $4 \% \mathrm{Ni}$ (also known as 13/4) is being used in fabrication of hydro turbine underwater parts. However, the maintenance repair of this steel is a primary cause of concern in its use. The quantity of martensite and its hardness are the main causes of weldability problems encountered with martensitic steels. Fully martensitic steels are air hardening and susceptible to hydrogen embrittlement. Austenitic stainless steel, on the other hand, has been widely preferred by industry due to its good mechanical properties, outstanding corrosion resistance in a wide range of environment and good weldability. However, there is a need to increase the strength level of this steel to meet the challenges forced by severe erosive conditions faced by hydro turbine underwater parts. In raising the strength of austenitic stainless steel, $\mathrm{N}$ alloying has been gaining much attention; because $\mathrm{N}$ is a strong solid solution hardener, has higher solubility in austenite than $\mathrm{C}$, and improves corrosion resistance. In addition, $\mathrm{N}$ increases grain size hardening (Ikegami and Nemoto 1996). Nitrogen solubility in austenite increases with $\mathrm{Mn}$ and $\mathrm{Cr}$ contents; the $\mathrm{N}$ alloying can be applied to $\mathrm{Cr}-\mathrm{Mn}$ and $\mathrm{Cr}-$ $\mathrm{Mn}-\mathrm{Ni}$ austenitic stainless steels.

In view of above, it is expected that nitronic steels can be developed as suitable alternative for martensitic stainless 
Table 1. Chemical composition of $13 / 4$ martensitic and $21-4-\mathrm{N}$ nitronic steel (wt \%).

\begin{tabular}{lcccccccccccc}
\hline Steel & $\mathrm{C}$ & $\mathrm{Si}$ & $\mathrm{Mn}$ & $\mathrm{Cr}$ & $\mathrm{Ni}$ & $\mathrm{N}$ & $\mathrm{S}$ & $\mathrm{Cu}$ & $\mathrm{Co}$ & $\mathrm{P}$ & $\mathrm{Mo}$ & $\mathrm{Fe}$ \\
\hline $13 / 4$ & 0.06 & 0.74 & $1 \cdot 16$ & $13 \cdot 14$ & 3.9 & - & 0.014 & 0.088 & 0.035 & 0.015 & 0.61 & Bal. \\
$21-4-\mathrm{N}$ & 0.56 & 0.25 & 9.90 & 23.42 & 4.28 & 0.38 & 0.001 & 0.16 & 0.06 & 0.041 & - & Bal. \\
\hline
\end{tabular}

steels in the fabrication of underwater parts in hydroelectric projects. In this paper results of a comparative study of erosion behaviour of martensitic steel (termed as 13/4 steel) and a nitronic steel (termed as 21-4-N steel) have been presented and analysed.

\section{Experimental}

The experimental task of this study includes optical and scanning electron microscopic analysis, hardness measurements, tensile tests, impact tests and erosion testing of an as cast martensitic stainless steel and a nitronic steel.

\subsection{Materials}

The 13/4 martensitic and $21-4-\mathrm{N}$ nitronic steels used in this investigation possess the chemical composition as given in table 1 . Long bars of $40 \times 40 \mathrm{~mm}$ cross-section were received from M/s Star Wire (India) Ltd., Ballabhgarh (Haryana). Specimens for metallographic examination, tensile tests, impact tests and erosion tests were machined from these bars.

\subsection{Metallographic analysis}

The samples of as cast steels were ground and polished in order to render them suitable for microscopic observation. Prior to this observation, the sample surfaces were etched with aquarazia. SEM study of eroded surfaces was conducted using LEO 435 VP scanning electron microscope at an accelerating voltage of $15 \mathrm{kV}$.

\subsection{Mechanical properties}

Hardness measurements were carried out on the Vickers hardness testing machine using a $30 \mathrm{~kg}$ load. Impact energy values were obtained by means of Charpy impact test using samples of dimensions $10 \times 10 \times 55 \mathrm{~mm}$ and the usual V-notch geometry. The tensile tests were performed as per ASTM E $8 \mathrm{M}-03$ to determine the values of ultimate tensile strength (UTS), yield strength (YS) and ductility (\% elongation).

\subsection{Erosion behaviour}

Samples measuring $40 \times 40 \times 10 \mathrm{~mm}$ were used for standard erosion tests. Silicon carbide particles of size $500-$
$700 \mu \mathrm{m}$ were used as erodent. The erosion test rig was fabricated as per the standard followed by Wood and Wheeler (1998) for conducting erosion tests by solid particle impingement using gas jets. The erosion tests were performed under well-controlled parameters like particle velocity, impingement angle, gas (air) pressure and test duration. The erosion test was conducted with particle velocity of $120 \mathrm{~m} / \mathrm{s}$ and the distance between the nozzle and target was kept at $10 \mathrm{~mm}$. The experiments were conducted at $30^{\circ}$ and $90^{\circ}$ impingement angles. The eroded surfaces were studied on SEM to identify the mechanism of erosion.

\section{Results}

\subsection{Microstructure}

Figure 1 shows the microstructures of 13/4 martensitic stainless steel and 21-4-N nitronic steel in as cast condition. The microstructure of $13 / 4$ martensitic stainless steel consists of packets of very fine, untempered lath/martensitic needles. Apart from these packets, the structure exhibits a second phase, which is $\delta$-ferrite. The as cast $21-4-\mathrm{N}$ steel, which is a nitrogen strengthened austenitic stainless steel having low $\mathrm{Ni}$ and higher concentration of $\mathrm{C}$, possesses predominantly austenitic phase along with the precipitates of carbides. The carbides may be any one or combinations of $\mathrm{M}_{23} \mathrm{C}_{6}, \mathrm{MC}, \mathrm{M}_{7} \mathrm{C}_{3}$ and $\mathrm{M}_{6} \mathrm{C}$, where $\mathrm{M}$ can be $\mathrm{Cr}, \mathrm{Fe}$, Mo and $\mathrm{Ni}$ (Padilha and Rios 2002). Among these carbides, the probability of formation of $\mathrm{M}_{23} \mathrm{C}_{6}$ appears low, since presence of $\mathrm{N}$ in the matrix is reported to suppress the precipitation of this carbide. The $\mathrm{M}_{6} \mathrm{C}$ $(\mathrm{M}=\mathrm{Fe}, \mathrm{Cr}, \mathrm{Mo}, \mathrm{W}, \mathrm{Nb}$ and $\mathrm{V})$ carbides are often found in austenitic stainless steels containing $\mathrm{Mo}, \mathrm{W}$ and $\mathrm{Nb}$. The $\mathrm{MC}(\mathrm{M}=\mathrm{Ti}, \mathrm{Zr}, \mathrm{Hf}, \mathrm{V}, \mathrm{Nb}$ and $\mathrm{Ta})$ carbides are very stable and invariably present in stabilized austenitic stainless steels such as AISI 321 (Ti stabilized). The $\mathrm{M}_{7} \mathrm{C}_{3}$ carbides can only be found in austenitic stainless steels for very high $\mathrm{C}$ : Cr ratio. Since the $21-4-\mathrm{N}$ steel has higher concentration of $\mathrm{N}$ and also possesses high $\mathrm{C}: \mathrm{Cr}$ ratio, the carbide precipitated in this steel may be $\mathrm{M}_{7} \mathrm{C}_{3}$. In the microstructural examination of this steel, the massive core of carbides (dark portion) is surrounded by an eutectic, which according to Padilha and Rios (2002) consists of austenite and carbides.

\subsection{Mechanical properties}

Table 2 shows the mechanical properties of 13/4 martensitic stainless steel and $21-4-\mathrm{N}$ nitronic steel studied in 

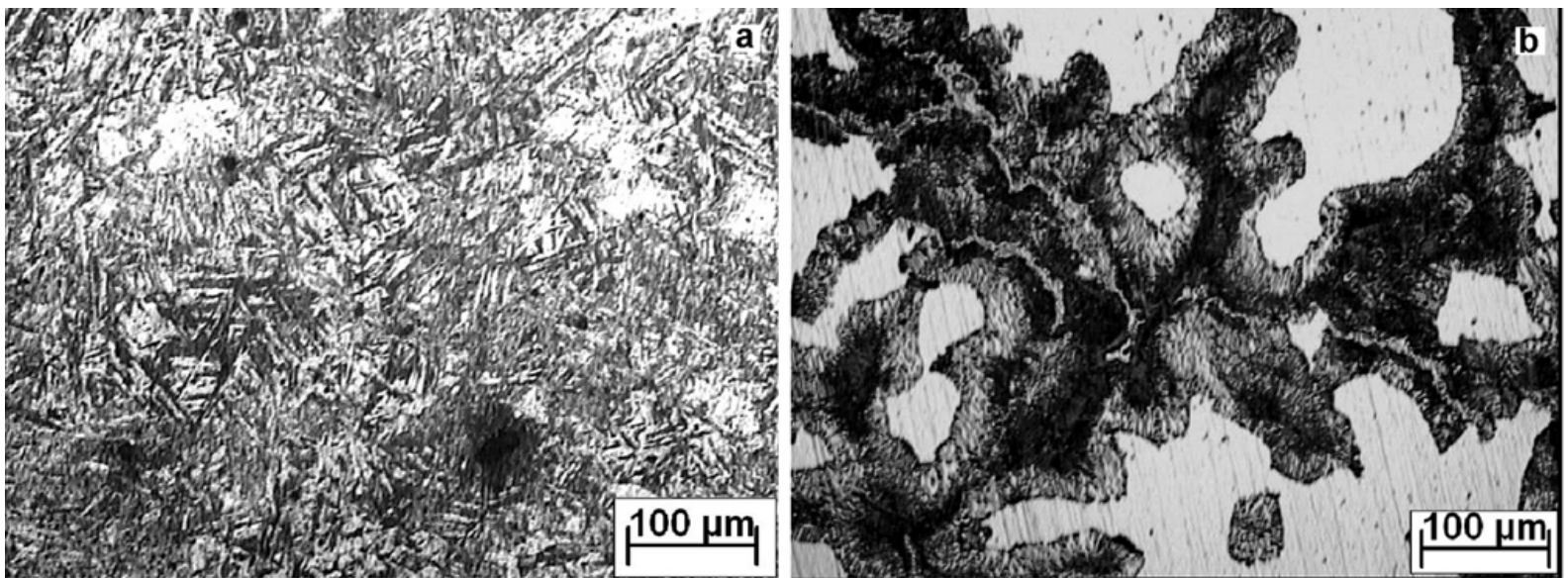

Figure 1. Microstructures of a. 13/4 martensitic stainless steel and b. 21-4-N nitronic steel.

Table 2. Mechanical properties of $13 / 4$ martensitic stainless steel and 21-4-N nitronic steel.

\begin{tabular}{lccccc}
\hline Steel & Hardness (VHN) & Impact energy (J) & YS (MPa) & UTS (MPa) & Ductility (\% el) \\
\hline $13 / 4$ & 305 & 64 & 899 & 930 & 14 \\
$21-4-\mathrm{N}$ & 320 & 9 & 466 & 676 & 17 \\
\hline
\end{tabular}
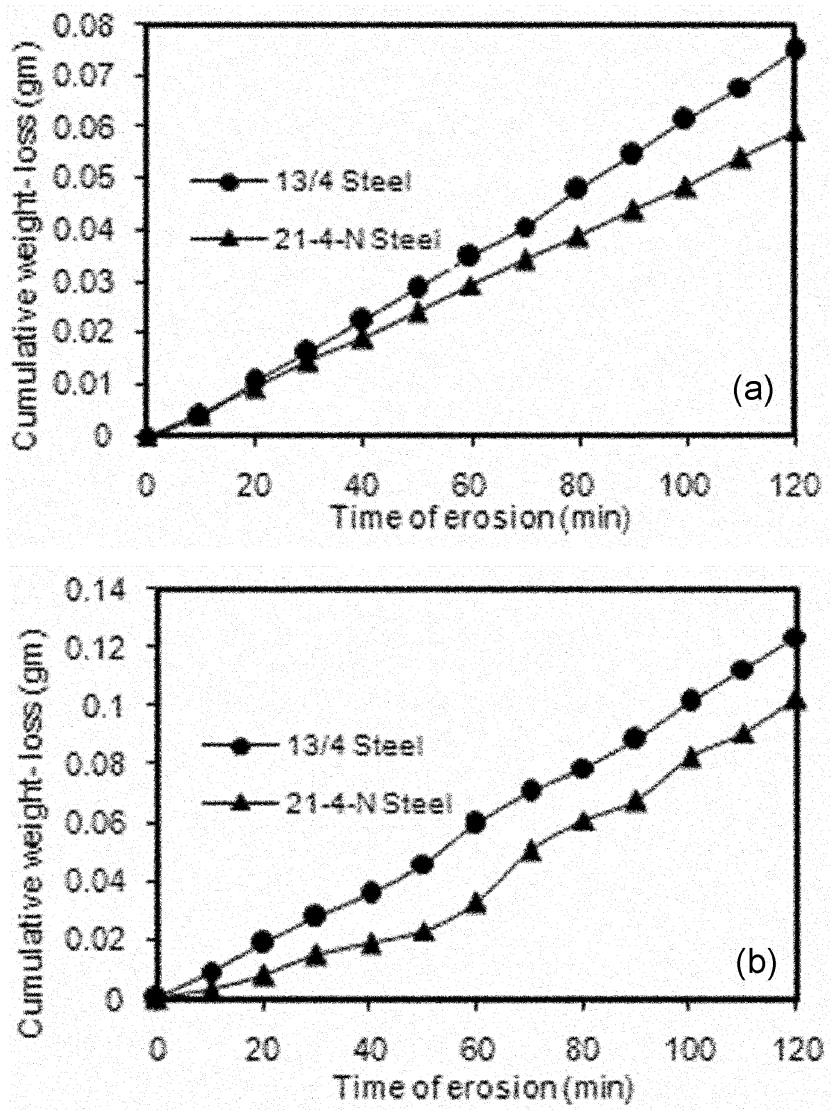

Figure 2. Cumulative weight loss as a function of erosion time at impingement angles of (a) $30^{\circ}$ and (b) $90^{\circ}$. this investigation. The 13/4 martensitic stainless steel possesses significantly higher values of impact energy, YS and UTS than the corresponding values in the 21-4$\mathrm{N}$ nitronic steel. The hardness and ductility (\% elongation) in martensitic stainless steel are marginally lower in comparison to nitronic steel.

\subsection{Erosion behaviour}

Erosion tests as described earlier were conducted on both the steels for a total duration of $2 \mathrm{~h}$ each and the weight loss was measured at every successive stage of $10 \mathrm{~min}$. Figure 2 gives the cumulative weight loss curves of the test materials at the impingement angles of $30^{\circ}$ and $90^{\circ}$. At both the impingement angles, the cumulative weight loss in martensitic stainless steel is more than that in nitronic steel. The slopes of erosion test curves given in figure 2 are almost constant except in case of nitronic steel at $90^{\circ}$ impingement angle. Variations in the slope of erosion curve may indicate variations in the mechanism of erosion damages during the erosion test. At $30^{\circ} \mathrm{im}-$ pingement angle the erosion loss is primarily due to shear cutting of surface material, whereas at $90^{\circ}$ impingement angle resultant erosion damage is due to strain hardening and embrittlement of target material. The $21-4-\mathrm{N}$ nitronic steel, owing to an austenitic matrix, is likely to undergo significant strain hardening and subsequent embrittlement leading to material loss. Irregular interaction between strain hardening and embrittlement may lead to variations 

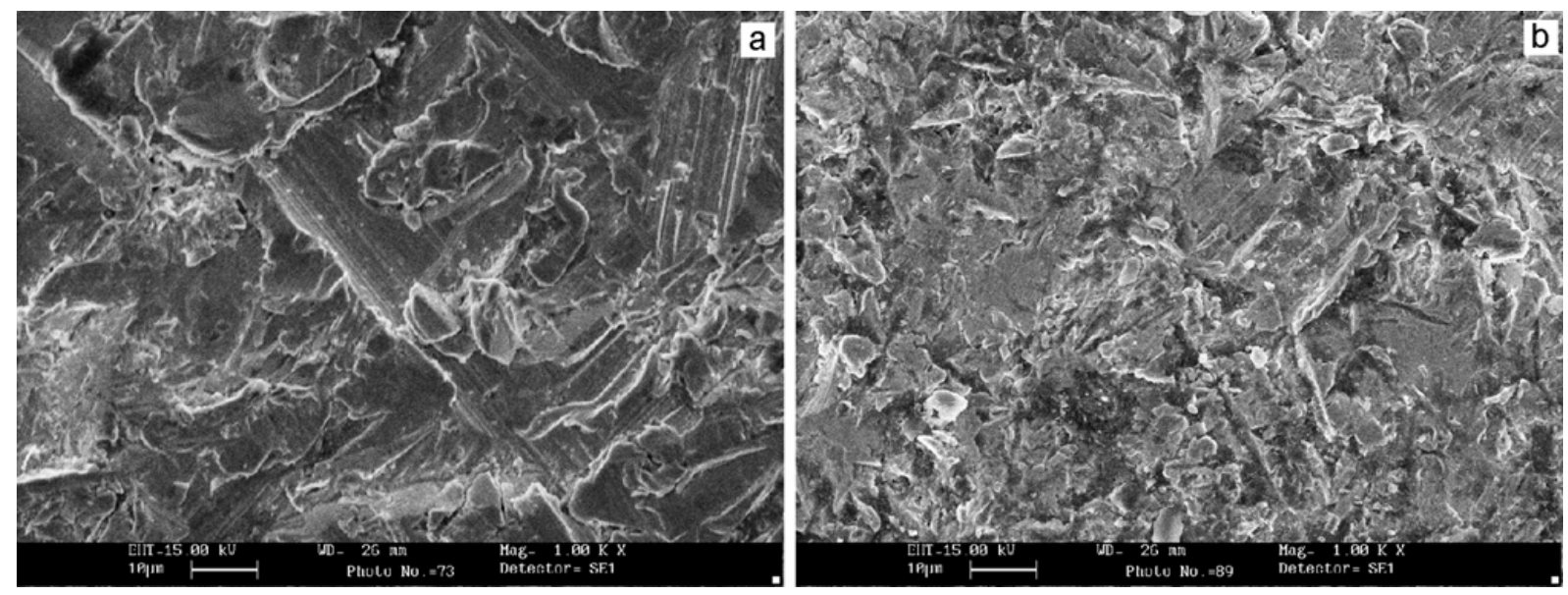

Figure 3. Scanning electron micrographs of eroded surfaces after $2 \mathrm{~h}$ of erosion test at $30^{\circ}$ impingement angle: a. $13 / 4$ martensitic stainless steel and b. 21-4-N nitronic steel.
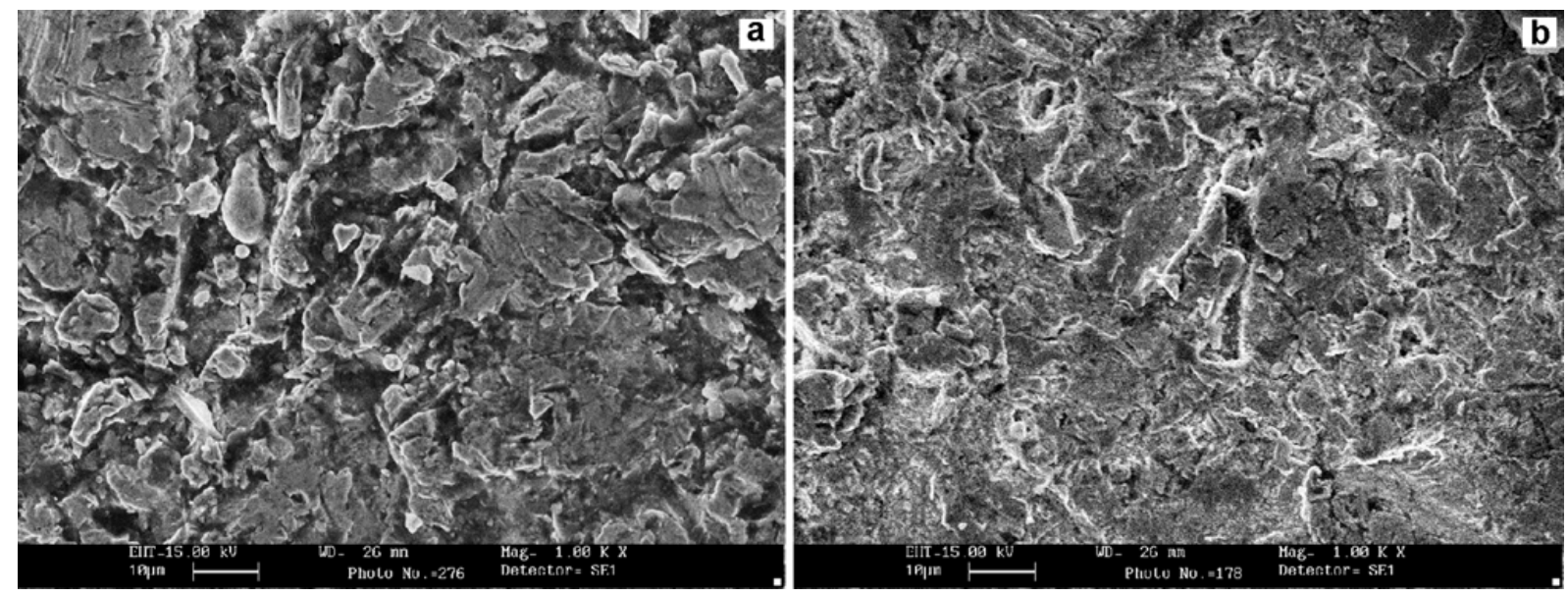

Figure 4. Scanning electron micrographs of eroded surfaces after $2 \mathrm{~h}$ of erosion test at $90^{\circ}$ impingement angle: a. 13/4 martensitic stainless steel and b. 21-4-N nitronic steel.

in the rate of material loss at various stages of erosion test. The 13/4 steel, being martensite, is less likely to undergo strain hardening and thus exhibits constant slopes at both $30^{\circ}$ and $90^{\circ}$ impingement angles.

\subsection{SEM study of eroded surfaces}

Figures 3 and 4 show the scanning electron micrographs of eroded surfaces of $13 / 4$ and $21-4-\mathrm{N}$ steels at impingement angle of $30^{\circ}$ and $90^{\circ}$, respectively. At $30^{\circ} \mathrm{im}-$ pingement angle the process of erosion involves a shear process. Thus the topography of eroded surfaces (figure 3 ) in both the steels indicates presence of ploughs, which are formed due to extrusion of platelets from the impact zone. Figure 3 also shows that the ploughs in 13/4 martensitic stainless steel are much wider than those in 21-4$\mathrm{N}$ steel, which indicates more erosion damages in the 13/4 martensitic stainless steel. At $90^{\circ}$ impingement an- gle, the eroded surfaces are almost free from ploughs. Deep surface cavities are instead observed (figure 4), which are created due to dislodging of material by hard hitting abrasive particles. Figure 4 also shows that at $90^{\circ}$ impingement angle, the cavities in 13/4 martensitic stainless steel are much deeper than those in 21-4-N steel. This is in agreement with more erosion damages (weightloss) observed in 13/4 steel.

\section{Discussion}

\subsection{Effect of microstructure}

The microstructure of target material plays an important role in solid particle erosion. The better erosion resistance of 21-4-N steel is attributed to stabilized austenitic structure. 21-4-N steel contains a heterogeneous microstructure consisting of two metallurgical phases, i.e. austenite 
and precipitated carbides. In solid particle erosion, austenite is considered to be a beneficial constituent because (i) austenite is plastic and tough; (ii) the strength at the interface between carbide and austenite is high (Xi and Zhou 1993) and (iii) localized strength of austenite increases with strain hardening (Soussan and Degallaix 1991). The better erosion resistance of $21-4-\mathrm{N}$ steel is also due to the distribution of hard carbides $\left(\mathrm{M}_{7} \mathrm{C}_{3}\right)$ in the matrix of austenite. In 21-4-N steel the austenitic matrix is continuous and the strength is high too, which are the beneficial parameters for erosion resistance (Levy 1981).

\subsection{Effect of hardness and ductility}

This investigation revealed that at both the impingement angles of $30^{\circ}$ and $90^{\circ}$ the erosion damages are more severe in 13/4 martensitic stainless steel as compared to the austenitic $21-4-\mathrm{N}$ nitronic steel. The mechanical properties play a vital role in determining the resistance to erosion of a target material. Primarily the hardness and ductility have been identified as main properties affecting erosion behaviour (Divakar et al 2005). High hardness coupled with high ductility leads to improved erosion resistance. High hardness is needed to counteract the effect of hard impinging particles. Ductility in the target material provides relief from high velocity particles by way of partial consumption of their kinetic energy in permitting localized deformation at impact sites, thus minimizing the chances of cracking. In the $21-4-\mathrm{N}$ nitronic steel the observed hardness $(320 \mathrm{VHN})$ and elongation (17\%) values are higher than the corresponding values $(305 \mathrm{VHN}$ and $14 \%$ ) in $13 / 4$ martensitic stainless steel. This explains to a large extent the better erosion resistance observed in 21-4-N nitronic steel. The role of impact energy and tensile strength does not appear to be significant in affecting the erosion behaviour in the steels studied in this investigation.

\subsection{Effect of tensile toughness}

It is observed that higher erosion resistance of $21-4-\mathrm{N}$ nitronic steel is also linked to its tensile toughness, which is higher than that of 13/4 steel. Figure 5 shows the engineering stress-strain diagram of both the steels. The tensile toughness of the 13/4 steel, as calculated from the area $\mathrm{ABCD}$ in the plastic range, is $68 \mathrm{MJ} \mathrm{m}^{-3}$, whereas for $21-4-\mathrm{N}$ steel, as calculated from the area EFGH, it is $73 \mathrm{MJ} \mathrm{m}^{-3}$. The tensile toughness of a material is its ability to absorb energy in the plastic range. It is represented by the area below the engineering stress-strain curve between the YS and fracture stress. Levin et al (1999) reported that tensile toughness is indicative of the ability of a material to absorb the energy of the abrasive particles impacted and have shown that a material having higher tensile toughness possesses higher erosion resistance.
This goes to show that during silt impact the tensile stresses developed contribute significantly towards the mechanism of erosion. Further, the role of impact energy, as determined by Charpy V-notch test, appears to be insignificant in the erosion damages. The $21-4-\mathrm{N}$ steel exhibits a better erosion resistance even though its impact energy $(9 \mathrm{~J})$ is much lower than that of the $13 / 4$ steel $(64 \mathrm{~J})$

\subsection{Effect of strain hardening}

The work hardening behaviour of the target material during solid particle impact also appears to be of critical importance. The austenitic grades of steels usually owe their wear resistance to their work hardening characteristics (Goretta et al 1991). Development of wear resistant Hadfield steel, for example, is primarily based on its self work hardening characteristics. The flow curve of many metals in their plastic range can be explained by the simple power curve relation

$$
\sigma=k \varepsilon^{n}
$$

where $n$ is the strain hardening exponent, $k$ the strength coefficient and $\sigma$ and $\varepsilon$ are, respectively true stress and true strain. The value of $n$ can be calculated from the log$\log$ plot of true stress and true strain curve after yielding. As seen in figure 6 , the values of $n$ so obtained are 0.07 and 0.46 for $13 / 4$ steel and $21-4-\mathrm{N}$ steel, respectively. A higher value of $n$ in case of 21-4-N steel is an indication of a higher rate of work hardening in the steel as compared to that in $13 / 4$ steel.

During erosion, impingement of silt particles causes localized elastic and plastic strains in the substrate material. These strains lead to in situ strain hardening in the sub surface region, which in turn causes resistance to wear and erosion. Steels with an austenitic matrix are more likely to develop in situ work hardening as compared to

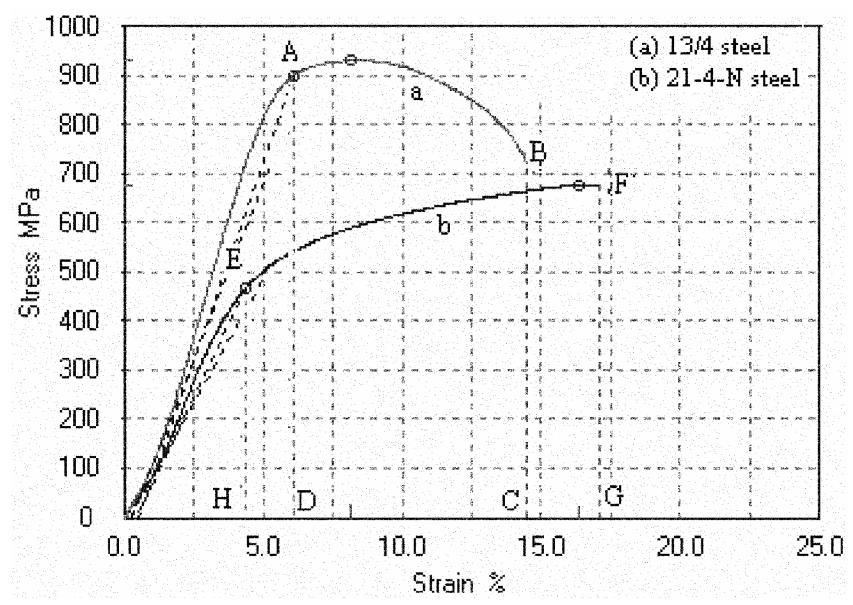

Figure 5. Engineering stress-strain diagram of a. 13/4 steel and b. 21-4-N steel. 

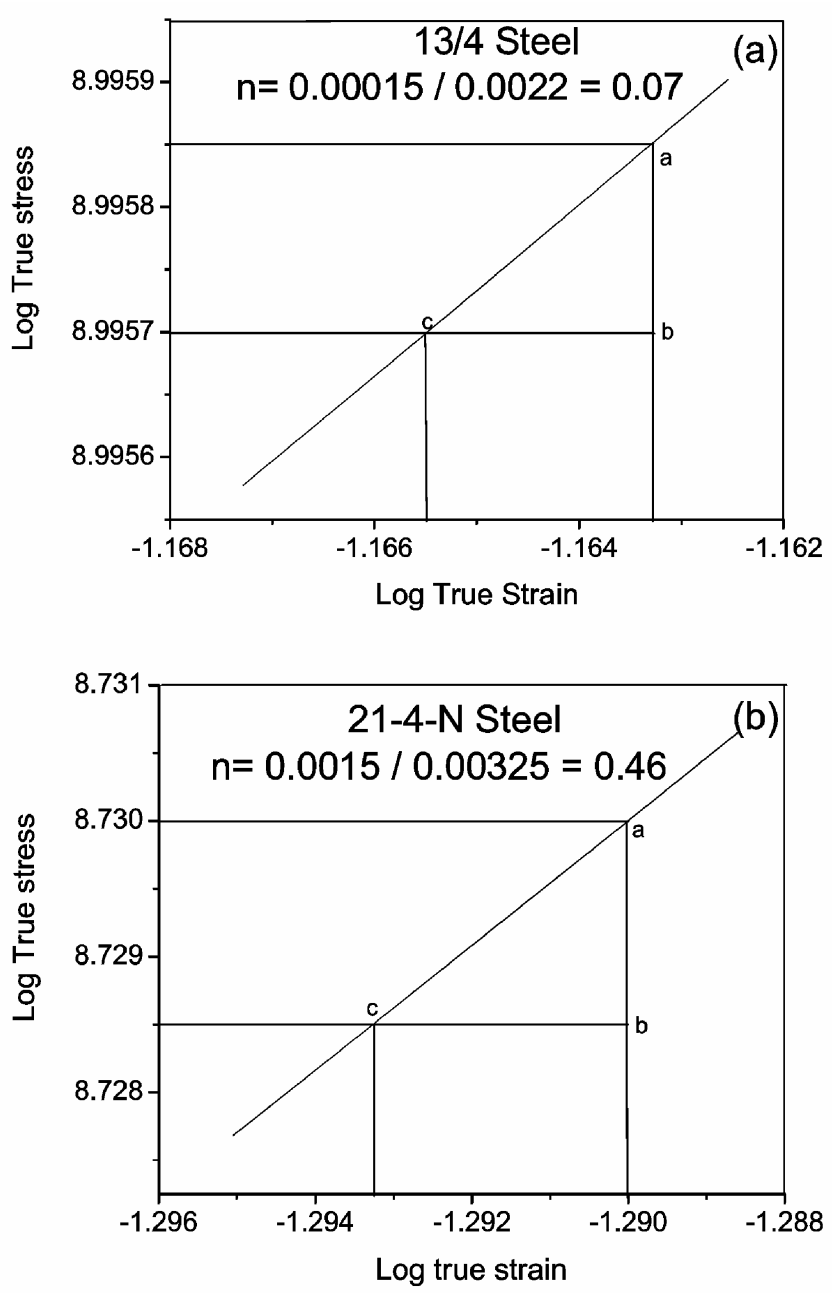

Figure 6. Work hardening exponent of (a) 13/4 steel and (b) 21-4-N steel.

those with a martensitic structure. In this context, the stacking fault energy of the austenitic matrix plays an important role, as low stacking fault energy may cause a high rate of work hardening. In Fe-Cr-Ni alloys, Schramm and Reed (1975) reported that $\mathrm{Cr}$ rapidly reduces the stacking fault energy. They have observed that $\mathrm{Ni}$ and $\mathrm{C}$ addition tend to increase the stacking fault energy while $\mathrm{Cr}, \mathrm{Si}, \mathrm{Mn}$ and $\mathrm{N}$ tend to decrease stacking fault energy in $\mathrm{Fe}-\mathrm{Cr}-\mathrm{Ni}$ austenitic alloys. The higher resistance to erosion in 21-4-N nitronic steel can, therefore, be attributed to the low stacking fault energy of its austenitic matrix.

During strain hardening, the gap between YS and UTS is also an important parameter, as it determines the stress range to which strain energy can be absorbed during plastic yielding prior to failure. As seen in figure 5, this stress range in $13 / 4$ steel is $31 \mathrm{MPa}$ against a stress range of $210 \mathrm{MPa}$ in $21-4-\mathrm{N}$ steel. This provides more opportunity for continued strain hardening and a better erosion resistance in 21-4-N steel in comparison to the 13/4 martensitic steel.
The SEM study shows that at $30^{\circ}$ impingement angle the erosion damages are primarily due to formation of plough with shear lips. At $90^{\circ}$ impingement angle the damages are due to dislodging of chunks of material in the surface layer of the target material. In both the cases in situ strain hardening due to impinging particles plays an important role. High rate of work hardening, as measured by the magnitude of work hardening index $n$, retards both ploughing and dislodging of particles from target surface. Thus high hardness coupled with high ductility as well as high strain hardening characteristics contribute significantly towards the erosion resistance of these steels.

\section{Conclusions}

(I) The erosion resistance of $21-4-\mathrm{N}$ nitronic steel investigated by means of solid particle impingement is higher than that of $13 / 4$ martensitic stainless steel.

(II) High erosion resistance of 21-4-N steel is due to the distribution of hard carbides in the matrix of stabilized austenite.

(III) Mechanical properties significantly affect the erosion resistance of target material. In 21-4-N nitronic steel, high resistance to erosion is due to (i) high hardness coupled with high ductility, (ii) high tensile toughness and (iii) high rate of strain hardening in comparison to $13 / 4$ martensitic stainless steel.

\section{Acknowledgements}

This investigation has been financially supported by Ministry of Power, Government of India. The steels used were supplied by M/s Star Wire (India) Ltd., Ballabhgarh (Haryana), India.

\section{References}

Ball A 1983 Wear 91201

Bitter J G A 1963 Wear 65

Divakar M, Agarwal V K and Singh S N 2005 Wear 259110

Finnie I 1960 Wear 387

Goretta K C, Arroyo R C, Wu C T and Routbort J L 1991 Wear 147145

Ikegami Y and Nemoto R 1996 ISIJ Int. 36855

Levin B F, Vecchio K S, Dupont J N and Marder A R 1999 Metall. \& Mater. Trans. A30 1763

Levy A V 1981 Acta Met. 111369

Mann B S 1998 Wear 21756

Mann B S 2000 Wear 237140

Ness E and Zibbell R 1996 Wear 196120

Oka Y I, Okamura K and Yoshida T 2005 Wear 25995

Padilha A F and Rios P R 2002 ISIJ Int. 42325

Schramm R E and Reed R P 1975 Metall. Trans. A6 1345

Sheldon G L and Kanhere A 1972 Wear 21195

Soussan A and Degallaix S 1991 Mater. Sci. \& Engg. A142 169

Sundararajan G and Shewmon P G 1983 Wear 84237

Wood R J K and Wheeler D W 1998 Wear 22095

Xi Z T and Zhou Q D 1993 Wear 162-164 83 